\title{
The Use of Dental Services among Older Australians: Does Location Matter?
}

\author{
Nerina Vecchio \\ Griffith Business School, Griffith University
}

Address for correspondence: Nerina Vecchio, BEc, MEcon, PhD (University of Queensland, Australia), Lecturer Economics, Griffith Business School, Griffith University Gold Coast Campus, PMB 50 Gold Coast Mail Center Queensland 9726 Australia. Tel.: +61-7-55528284; fax: +61-7-5552 8068. E-mail: n.vecchio@griffith.edu.au

\begin{abstract}
Based on the National Health Survey of 2005, this study examined the use of dental services among non-institutionalised older Australians. The results of the regression revealed differences in the frequency of dental visits across the States. The greater the public dental health expenditure per capita in each state the more likely residents of that state were to have visited the dentist in the previous year. Older people residing outside major cities experienced the greatest disadvantage. In addition to the socioeconomic factors reported by studies, in Australia inequalities in access to dental health services was associated with urbanicity and Australian states.
\end{abstract}

\section{Introduction}

Australia’s dental generations report of 2004-2006 (Slade et al. 2007) revealed that although the rates of tooth loss have dramatically declined, untreated decay particularly among older people has become an issue. The prevalence rates of root decay and periodontitis of those aged 74 and over were three times greater than the general population. These findings support Australia's National Oral Health Plan ( $\underline{\mathrm{NACOH} 2004})$ that places older adults as a priority group (Slade et al. 2007, p. 237). 
Public good and market failure arguments are often given as reasons for government involvement in health care. The cornerstone of these arguments is that public funding of health services alleviates poverty (Keating 2000). Since rising demand for health services is associated with an ageing population, older people may be particularly vulnerable to poverty.

In recognition of this vulnerability the Australian Commonwealth and state governments have traditionally funded dental health services. However, the Commonwealth's withdrawal of the Dental Health Program in late 1996 led to each state responding differently to counteract the withdrawal of funding. Consequently, among the states, considerable differences exist in the adequacy of dental care. Furthermore, the inequalities in dental health services between the states may be compounded by the geographical location within each state. This study investigates the issue of location and the use of dental health services among older Australians.

Although Australia does have universal health coverage, 80-90 per cent of dental care is delivered privately through fee for service (Schwarz 2006). Excluding medications (27.8 per cent), dental services (20.1 per cent) account for the greatest proportion of out of pocket health expenditure by individuals followed by aids and appliances (17.8 per cent) and medical services (9.6 per cent) (IHW 2006).

The recent publication by Slade et al. (2007) provides discussion on the use of dental services by Australians. Based on the data collected from the National Survey of Adult Oral Health, their study found that those born before the 1950s had profoundly greater levels of tooth loss and tooth replacement than more recent generations. Approximately one half of adults usually visited a dentist at least once a year. More than four-fifths of Australian adults attended private dentists and 91 per cent paid out of pocket for the visit. Favourable patterns of dental attendance were more likely among dentate people, the insured, those residing in capital cities and people with higher levels of schooling. Those less likely to exhibit favourable patterns of dental care were indigenous Australians and those eligible for public dental care.

Traditionally research in economics has focused on the association between dental services and economic factors (Conrad et al. 1987; Grembowski et al. 1987; Nguyen et al. 2005; Tianviwat et al. 2007; Jamieson and Thomson 2006; Grytten and Holst 2002). There is, however, evidence in the Australian research that location is also important (Ringland et al. 2004; Adams et al. 2004; Armfield et al. 2006). Adams et al. (2004) determined that Western 
Australians in rural and remote areas visited a dental professional less frequently than people residing in urban areas. The study concluded that for older Western Australians, geographical location was a major factor in the frequency of dental service visits and the reason for dental visits. This link between dental care and location is supported by Armfield et al. (2006). Of a sample of older people residing in New South Wales, Ringland et al. (2004) found that edentulism was associated with living in a rural area. Other influential factors included being older, no private dental insurance, being female, leaving school at less than 15 years of age, financially insecure, non-homeowner and unable to travel alone (Ringland et al. 2004).

There is consensus among Australian researchers of a link between residing in remote areas and the lower use of dental services. Yet little research exists relating to the differences in the use of dental services among the Australian states and territories. Instead, the majority of Australian studies are confined to investigations of one state (Ringland et al. 2004; Armfield et al. 2006; Adams et al. 2004). National studies are descriptive and do not control for confounding variables (Slade et al. 2007; Schwarz 2006). The aim of this study is to understand the impact of location, represented by remoteness and state, on the use of dental services among non-institutionalised (those residing in private dwellings) older Australians after controlling for influential factors identified in the literature.

\subsection{Fluoridation in Australia}

To better interpret the findings of the analysis, an understanding of fluoridation is warranted. Fluoridation in water was introduced in Townsville, Tasmania and the Australian Capital Territory (ACT) in 1964, Perth and Sydney in 1968, Adelaide in 1971, Darwin in 1972 and Melbourne in 1977 (Queensland Government 2008). By 1977 all Australian capital cities, with the exception of Brisbane, had fluoridated water. Today all residents of the ACT have fluoride in their tap water, along with 91 per cent of Tasmanian residents, 90 per cent in New South Wales, 86 per cent in Western Australia, 77 per cent in Victoria and 70 per cent in the Northern Territory. Less than 5 per cent of Queenslanders have access to fluoridated water (Queensland Government 2008).

Australia's dental generations report (Slade et al. 2007) concluded that while Australia's fluoride generation had substantially better oral health than the previous generation, most of the benefit accrued during childhood (Slade et al. 2007, p. 231). Widespread exposure to fluoride in drinking water and toothpaste did not immunise the fluoride generation against decay. Adults during the 17 years preceding the 2004-2006 survey 
developed decay in previously healthy teeth at an equal rate to that of their parents' generation who were not exposed to fluoride in childhood. Meanwhile, older generations that retained historically high numbers of teeth were found to continue to develop decay in previously healthy teeth as they aged (Slade et al. 2007, p. 236).

Since the study reported here is an investigation of the pre-'fluoride generation' and most of the benefits of fluoridation accrue in childhood, it is an assumption of this study that fluoridation within different locations has little impact on the dental health of older Australians.

\section{Method}

\subsection{Study Population}

The cross-sectional analysis is based on the National Health Survey (2005) data collected between 2004 and 2005. The National Health Survey (ABS 2005), conducted throughout Australia in the months of August 2004 to July 2005, covered people in both urban and rural areas in all states and territories. Trained interviewers from the Australian Bureau of Statistics (ABS) collected the household component of the data survey from a sample of 19501 private dwellings (ABS 2006). Within each selected household a random subsample of usual residents were selected for inclusion in the survey.

The inclusion criteria for this study were that individuals be aged 65 and over, reside in private dwellings in one-family households, including lone households. This resulted in the unweighted sample size of 3750. The ABS supplied the weightings (person weights) in the NHS CURF (National Health Survey, Confidential Unit Record File) dataset providing an estimated population of 2440052 .

\subsection{The Model}

It is widely recognised that frequent dental visits assist in maintaining dental health through the early detection of tooth and gum problems and oral cancers (Hay et al. 1982). This in turn reduces the cost burdens in the public and private sector (Adams et al. 2004).

The frequency of dental visits was determined in Equation (1),

Dental visits $_{\mathrm{i}}=\beta_{0}+\beta_{1}$ Remote $_{\mathrm{i}}+\beta_{2}$ State $_{\mathrm{i}}+\beta_{3} \mathrm{X}_{\mathrm{i}}+\varepsilon_{\mathrm{I}}$ 
The dichotomous dependent variable of Dental visits represented those that consulted a dental professional within the year, 1 if yes, 0 if no. This variable expressed the odds of visiting a dental professional during the last 12 months. The explanatory variables under investigation related to location, that is, Remote and State. In the model the Remote variable was recorded as categorical ( 1 if city, 2 if regional, 3 if other 'major city' was the referent). This captured information about the distance to a dental professional and the dentist ratio. The categorical variable State captured differences relating to State funding. 'New South Wales' was the referent. Note that the state and urbanicity variables also captured unobserved factors about that area such as disease prevalence and access to other health services.

Certain sociodemographic characteristics identified in previous studies as important in the use of dental services were also included in the model. $X_{i}$ became the vector of variables that affected dental visits such as income, insurance, health status, age, concession card, gender, education and country of birth.

Bendall and Asubonteng's (1995) review of several US studies revealed that family income impacted positively on the demand for dental care. Outside the United States the findings relating to income and dental care are similar (for example, Nguyen et al. 2005; Tianviwat et al. 2007; Jamieson and Thomson 2006; Grytten and Holst 2002). Since decisions within the household are usually made at the family level, in this study family income was chosen as an explanatory variable. This specification is consistent with other studies in this field (Grytten et al. 1993; Turrell et al. 2007; Grytten and holst 2002; Hay et al. 1982; $\underline{\text { Adams }}$ et al. 2004). The gross weekly equivalised cash household income in deciles (first decile, lowest, to the tenth decile, highest) represented family income. The 'modified OECD' equivalence scale, used by the ABS, has wide acceptance among Australian analysts ( $\underline{\mathrm{ABS}}$ 2004). The equivalence scales allowed adjustments to the actual income of households so as to capture the relative wellbeing of a household of different size and composition.

Dental insurance positively impacts on the demand for dental services ( 1982). Since older people typically possess lesser dental coverage due to their limited financial resources, they are less likely to seek dental care (refer to Bendall and Asubonteng 1995, for a review of the literature). The model represented insurance as two categories (ancillary cover and no insurance). Although dental fees could not be included in the model, private health insurance captured to some extent the cost of dental care to the individual. 
A large body of literature identifies self-reported health as highly correlated with medically determined health status (see Cai 2007). A link also exists between health status and oral health. Certain diseases (e.g. diabetes, cancer) or concomitant diseases and the use of drugs may contribute to poorer dental health (Pajukoski et al. 1999; Sandberg et al. 2000). Given the limited information relating to the need of dental services within the dataset, selfreported health became a proxy for need. Self-reported health in this study was represented by the self-reported health status (poor, fair, good, very good, excellent; 'excellent' became the referent).

The National Health Survey (ABS 2005) dataset did not report the proportion of older people with edentulism. The variable age became a proxy for edentulism. Age reflected the historical aspect of dental treatment as well as the effects of a deterioration of oral health with the passage of time. For those born in the first half of the twentieth century the predominant surgical approach was teeth extraction. Slade and colleagues (2007, p. 201) report that the prevalence of complete tooth loss tends to be affected more by year of birth than the passage of time. In this study age was recorded in the model as an ordinal variable from 65 years in five year intervals up to 85 and over.

Previous research found that among those 65 and older, holding a pensioner concession card or health care card decreased the likelihood of a dental check-up compared to non card holders (AIHW 2002). The model included the possession of a government health concession card (1 yes, 0 no) as a dichotomous variable.

The standard demographic variables such as country of birth (reference group was 'non-English speaking country'), education ('Basic skill vocational' was referent) and gender ('male' became the referent) were also included in the model.

\subsection{Data Analysis}

Initially a profile of older people's use of dental services was presented. A $\chi^{2}$-test of independence tested for significant associations. The association between dental usage and the explanatory variables was analysed using a binary logistic regression.

\section{Results}

A statistical summary of the weighted population is presented in Table 1. The characteristics of older Australians are segregated by dental care utilisation in the previous 12 
months - those that did consult a dental professional $(n=903780)$ and those that did not ( $n=1432$ 045). A greater proportion (61.3 per cent) of older Australians reported that they did not receive dental services during the previous 12 months.

Of the individuals that did consult a dental professional, the majority did not hold a government concession card, tended to be male, resided in major cities and were younger in age. Also, those with private health insurance and higher educational attainment dominated this group. The use of dental services increased with family income and general health assessment.

\subsection{Influences of Dental Service use Among Older People}

The results of the binary logistic regression, including the odds ratios and 95 per cent confidence intervals are presented in Table 2. The regression model resulted in a Nagelkerke $R^{2}$ of 14 per cent. With the exception of the concession card estimate, all the estimates for the control variables were statistically significant $(P<0.001)$.

The location of older people within different regions and among Australian states was associated with the frequency of dental visits. Individuals residing in regional and remote areas reported lower odds, 0.684 and 0.799 respectively, of using dental services in the previous year compared with households residing in cities. In comparison to New South Wales, the estimated odds of Queensland residents using dental services in the previous year increased by 21 per cent. Apart from Queensland, and to a lesser extent South Australia, other states had lower odds of visiting a dental professional in the previous year compared with older people residing in New South Wales.

Individuals with ancillary private health insurance had 1.915-fold the odds of using the dental service in the past 12 months compared with those without cover. For those without private health insurance, the estimated odds of using dental services within the past 12 months decreased compared with those with private health insurance. The estimated odds of dental service use increased, on average, by 8 per cent with each successively higher income decile.

In comparison with those aged between 65 and 69, the odds of dental service use decreased with older cohorts. This reflects the increase in edentulism experienced by people as they age and the changes in dental treatment overtime. Individuals from non-English speaking countries had greater odds of visiting a dental professional than those born in 
Australia or other English speaking countries. As health deteriorated the odds of visiting the dentist lowered.

\subsection{Influences of Dental Service use Among Older People by State}

Further regression analysis segregating the data by each Australian state was performed to clarify the associations between urbanicity and state. Table 3 reports the estimates for location as well as family income and concession card, after controlling for other confounding variables in the dental visits model.

Referring to Queensland, South Australia, and Western Australia and the Northern Territory, the odds of dental service usage decreased as the geographical distance from the capital city became greater. In contrast, those residing in remote New South Wales had 1.29fold the odds of using dental services in the previous year than older people residing in Sydney. The estimated odds in regional Tasmania increased by 8 per cent compared with those of Hobart. In regional and remote Victoria older people had 0.479-fold and 0.694-fold, respectively, the odds as those in Melbourne to do so.

For most states the odds of dental service utilisation increased on average between 7 per cent and 15 per cent with each successively higher income decile. Interestingly, in Victoria income was less important in the prediction of the use of dental services.

\section{Discussion and Conclusion}

This study examined the link between location and the use of dental services among non-institutionalised older Australians. It extended previous research by identifying and explaining differences among the Australian states. The higher prevalence of untreated decay among older people compared with others (Slade et al. 2007) highlights the importance of investigating dental service usage among older Australians.

The regression analysis confirmed the conclusions reached by other Australian studies that socioeconomic factors are strongly associated with dental visits (Slade et al. 2007; $\underline{\text { Adams }}$ et al. 2004; Armfield et al. 2006; Ringland et al. 2004). In particular, this study found a strong 
and positive link between dental visits and factors such as private health cover, ${ }^{1}$ residing in capital cities and higher levels of education.

While it was found that socioeconomic factors did matter in the demand for dental services, this study also confirmed the importance of location in association with the use of dental services. Possible explanations for this include the differences in public funding towards dental services across the Australian states and the distance among regions within each state.

The state in which an individual resided played an influential role in the frequency of dental visits. In Queensland the odds of residents visiting a dentist in the previous year increased by 21 per cent compared with those residing in New South Wales. In comparison to New South Wales, other States, except South Australia, reported a decrease in dental visits (refer Table 2).

The Commonwealth’s withdrawal of the Dental Health Program in late 1996 led to a dramatic increase in the waiting times for dental care. The different responses by the states to counteract the withdrawal of funding have led to considerable differences in the adequacy of dental care within each state (Schwarz 2006). For instance, the Queensland government allocates around \$33 per capita in dental health compared with \$21 per capita by the New South Wales government (AIHW 2006). Referring to Table 4, it is interesting to note a positive relationship between the odds of visiting a dentist and expenditure on dental health resources per capita in each state. The relative difference in visits across the States reflects the public expenditure per capita of each state.

The importance of location was further highlighted by the differences in dental visits among urban, regional and remote locations. Individuals residing in remote areas visited the dentist less in the previous year compared with urban residents. Other researchers have reported similar findings (Ringland et al. 2004; Adams et al. 2004; Armfield et al. 2006). The greater concentration of dentists in urban areas ( $\underline{\text { Schwarz 2006) }}$ explains the result. Older people residing outside major cities experienced the greatest disadvantage, particularly those residing in the regional areas of Victoria and New South Wales and the remote areas of South Australia, Western Australia and the Northern Territory, and Queensland (refer Table 3).

\footnotetext{
${ }^{1}$ The ABS ( $\underline{\text { ABS 2006) }}$ reported that 64 per cent of those without private cover stated that they "can’t afford it/too expensive”.
} 
When the analysis was segregated by state it was found that the direction of the association between holding a concession card and dental visits depended on the state in which an individual resided. Holding a concession card in Victoria, Queensland, and Western Australia and the Northern Territory were associated with an increase in dental visits compared with non-card holders. The opposite held for New South Wales, South Australia and Tasmania.

The mixed results may reflect the differences among the states in the eligibility criteria for the concession card. Schwarz (2006) reports an excess demand from concession cardholders for dental care with waiting lists of five years or more in some areas. In New South Wales the eligibility criteria for public dental services are the most generous of all states. Approximately 50 per cent of this state's population is estimated to be technically eligible for care compared with approximately 30 per cent in Victoria and Queensland (Schwarz 2006). The decrease incidence of dental visits among concession card holders compared with non-cardholders in New South Wales suggests that the demand created by the generous eligibility criteria has increased the waiting time of dental services within that state. In contrast, the findings of the 'less generous' states, that is Victoria and Queensland, implies that those holding concession cards have better access to dental services than noncardholders. The differing patterns of dental visits among concession card holders within each state highlight the ineffectiveness in widening the eligibility criteria without considering the adequate supply of dental services.

With the exception of Victorian residents, dental visits by others were responsive to income. For older Victorians the concession card rather than income was more important in determining dental visits.

Limitations of this study included data restrictions that did not allow the inclusion of the variable that represented edentulism in the model. Age became a proxy for edentulism. Other variables omitted from the model included specific treatment received by the client. Since the state and urbanicity variables captured all unobserved factors about that area, it could not be easily concluded from the analysis that differences across areas were caused by differences in public funding.

Since greater frequency in the use of dental services improves dental health, governments have an incentive to ensure that individuals access dental services on a regular 
and frequent basis. Doing so will minimise the deterioration of oral health and this in turn will ease pressure on the dental health care system.

While the majority of Western countries must contend with socioeconomic factors that impact on dental health, for Australia the issue is further compounded by inequitable access to resources based on location. Although 80-90 per cent of dental care is delivered privately, the findings reported here reveal that differences in public funding among the Australian states may play a role in the use of dental services among older people. Governments have a responsibility to reduce poverty. Involvement by government through equitable access to dental health care assists in this objective.

First version received November 2007;

final version accepted March 2008 (Eds).

\section{Endnote}

\section{References}

Adams, C., Slack-Smith, L., Larson, A. and O’Grady, M. 2004, 'Dental visits in older Western Australians: A comparison of urban, rural and remote residents', Australian Journal of Rural Health, vol. 12, pp. 143-49.

Armfield, Slade, G. and Spencer, A. 2006, Socioeconomic differences in children's dental health, AIHW, Canberra.

Australian Bureau of Statistics 2004, Household Expenditure Survey and Survey of Income and Housing: User Guide, 2003-04, Cat. no. 6503.0, ABS, Canberra.

Australian Bureau of Statistics 2006, National Health survey: Summary of Results, 2004-05, Cat. no. 4364.0, ABS, Canberra.

Australian Bureau of Statistics 2005, National Health Survey CURF, Cat. no. 4324.0, ABS, Canberra.

Australian Bureau of Statistics 2007, Consumer Price Index, Australia, Mar 2007. Cat. no. 6401.0, ABS, Canberra.

Australian Institute of Health and Welfare 2006, Health Expenditure Australia 2004-2005, AIHW, Canberra.

Australian Institute of Health and Welfare 2002, Rural oral health and access to dental care 1994-96 and 1999, Dental Statistics and Research Unit, AIHW, Adelaide. 
Bendall, D. and Asubonteng, 1995, 'The effect of dental insurance on the demand for dental services in the USA: a review', Journal of Management in Medicine, vol. 9, pp. 5568.

Cai, L. 2007, 'Effects of Health on Wages of Australian Men'. Working Paper No. 2/07, Melbourne Institute, University of Melbourne, Melbourne.

Conrad, D., Grembowski, D. and Milgrom, P. 1987, ‘Dental care demand: insurance effects and plan designs', Health Services Research, vol. 22, p. 341.

Grembowski, D., Conrad, D. and Milgrom, P. 1987, 'Dental care demand among children with dental insurance’, Health Services Research, vol. 21, p. 755.

Grytten, J. and Holst, D.] 2002, 'Do young adults demand more dental services as their income increase?’, Community Dentistry and Oral Epidemiology, vol. 30, pp. 463 69.

Grytten, J., Holst, D. and Laake, P. 1993, ‘Accessibility of dental services according to family income in a non-insured population', Social Science and Medicine, vol. 37, pp. 1501-508.

Hay, J., Bailit, H. and Chiriboga, D. 1982, ‘The demand for dental health’, Social Science and Medicine, vol. 16, pp. 1285-1289.

Jamieson, L. and Thomson, W. 2006, ‘Adult oral health inequalities described using areabased and household-based socioeconomic status measures', Journal of Public Health Dentistry, vol. 66, pp. 104-09.

Keating, M. 2000, 'Lessons from the market place for health and human services', The Australian Economic Review, vol. 33, no. 2, pp. 198-204

National Advisory Committee on Oral Health (NACOH) 2004, Healthy mouths, healthy lives. Australia's National Oral Health Plan, 2004-2013, Australian Health Ministers' Conference, Canberra.

Nguyen, L., Hakkinen, U. and Rosenqvist, G. 2005, 'Determinants of dental service utilization among adults - the case of Finland', Health Care Management Science, vol. 8, pp. 335-45.

Pajukoski, H., Meurman, J., Snellman-Gröhn, S.] and Sulkava, R. 1999, 'Oral health in hospitalised and nonhospitalised community-dwelling elderly patients', Oral Surgery, Oral Medicine, Oral Patholology, Oral Radiology, Endod, vol. 88, pp. 437-43.

Queensland Government 2008, ‘Fluoridation in Australia’, viewed February 2008

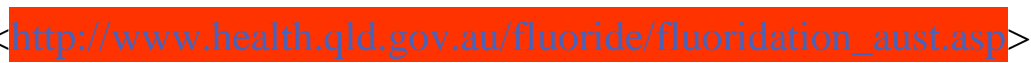


Ringland, C., Taylor, L., Bell, J. and Lim, K. 2004, ‘Demographic and socio-economic factors associated with dental health among older people in NSW', Australian and New Zealand Journal of Public Health, vol. 28, pp. 53-61.

Sandberg, G., Sundberg, H., Fjellstrom, C. and Wikblad, K. 2000, 'Type 2 diabetes and oral health: A comparison between diabetic and non-diabetic subjects', Diabetes Research and Clinical Practice, vol. 50, pp. 27-34.

Slade, G. D., Spencer, A. J. and Roberts-Thomson, K. F. (eds) 2007, Australia's dental generations: the National Survey of Adult Oral Health 2004-2006. AIHW cat no. DEN 165. AIHW, Canberra, (DSRU Series No. 34).

Savage, E. 2001, 'Policy Forum: The economics of health and health policy. Health and welfare measurement', The Australian Economic Review, vol. 34, no. 3, pp. 332-5.

Schwarz, E. 2006, 'Access to oral health care - an Australian perspective', Community Dentistry and Oral Epidemiology, vol. 34, pp. 225-31.

Tianviwat, S., Chongsuvivatwong, V. and Birch, S. 2007, 'Different dental care setting: Does income matter?’ Health Economics, in press.

Table 1 Selected Demographic Characteristics of Older People by Consulted a Dental Professional During the Previous Twelve Months

\begin{tabular}{|c|c|c|c|}
\hline & & \multirow[t]{2}{*}{ Total \% } & \multirow{2}{*}{$\begin{array}{l}\text { Consulted dental professonal } \\
\text { in previous } 12 \text { months (\% } \\
\text { row) }\end{array}$} \\
\hline & & & \\
\hline Total sample ( $n=3750$ unweighted) & & 100 & 38.7 \\
\hline \multirow[t]{8}{*}{ State/Territory } & New South Wales ${ }^{b}$ & 35.7 & 40.4 \\
\hline & Victoria & 25.9 & 32.7 \\
\hline & Queensland & 17.8 & 43.6 \\
\hline & South Australia & 8.8 & 41.9 \\
\hline & Western Australia & 8.9 & 41.0 \\
\hline & Tasmania & 2.7 & 24.9 \\
\hline & Northern Territory & 0.2 & 16.9 \\
\hline & TOTAL & 100 & \\
\hline ASGC remoteness area category & Major cities of Australia & 64.8 & 42.7 \\
\hline
\end{tabular}




\begin{tabular}{|c|c|c|c|}
\hline & Inner regional Australia & 22.3 & 30.1 \\
\hline & Other areas & 12.9 & 33.2 \\
\hline & TOTAL & 100 & \\
\hline \multirow[t]{3}{*}{ Sex of person } & Female & 54.1 & 36.6 \\
\hline & Male & 45.9 & 41.2 \\
\hline & TOTAL & 100 & \\
\hline \multirow[t]{6}{*}{ Age of person in years } & $65-69$ years & 30.5 & 45.8 \\
\hline & 70-74 years & 25.0 & 38.8 \\
\hline & 75-79 years & 21.8 & 37.2 \\
\hline & 80-84 years & 14.7 & 28.6 \\
\hline & 85 years and over & 8.0 & 33.5 \\
\hline & TOTAL & 100 & \\
\hline \multirow[t]{4}{*}{ Type of private health insurance cover } & Ancillary cover & 32.7 & 56.3 \\
\hline & Hospital & 44.8 & 49.9 \\
\hline & No private health insurance & 53.3 & 28.6 \\
\hline & TOTAL & $N^{c}$ & \\
\hline \multirow[t]{3}{*}{ Government health concession card } & Yes & 91.3 & 36.5 \\
\hline & No & 8.1 & 58.2 \\
\hline & TOTAL & 100 & \\
\hline \multirow[t]{5}{*}{$\begin{array}{l}\text { Highest level of post-school educational } \\
\text { attainment }\end{array}$} & $\begin{array}{l}\text { Higher degree, Post-grad dip, Bch } \\
\text { degree }\end{array}$ & 6.7 & 61.4 \\
\hline & Undergraduate/Associate diploma & 6.7 & 57.3 \\
\hline & Basic/ Skilled vocational & 20.9 & 39.8 \\
\hline & No post-school qualification & 65.7 & 34.1 \\
\hline & TOTAL & 100 & \\
\hline \multirow[t]{5}{*}{ General health assessment } & Excellent & 10.9 & 47.9 \\
\hline & Very good & 24.8 & 43.4 \\
\hline & Good & 32.0 & 38.1 \\
\hline & Fair & 21.4 & 33.8 \\
\hline & Poor & 10.8 & 29.8 \\
\hline
\end{tabular}




\begin{tabular}{lll|l}
\hline & TOTAL & $\mathbf{1 0 0}$ & 37.3 \\
\hline Country of Birth & Australia & 66.2 & 39.6 \\
& Mainly English speaking country & 14.5 & 42.8 \\
\hline & Non English speaking country & 19.3 & $\mathbf{1 0 0}$ \\
\hline
\end{tabular}

Notes: (a) $P>0.001 ; \chi^{2}$-test;

b. ACT State (1.2 per cent of total) included in NSW figures;

c. Respondents may have both ancillary and hospital cover so the total figure becomes greater than 100 per cent.

Source: Derived from the National Health Survey 2004-2005 (ABS 2005)

Table 2 Characteristics of Older People Who Consulted a Dental Professional During the Previous Twelve Months Compared with Those that Did Not, Australia, 2005

\begin{tabular}{|c|c|c|c|c|c|}
\hline & \multirow[t]{2}{*}{$B$} & \multirow[t]{2}{*}{ S.E. } & $\begin{array}{l}\text { Adjusted Odds } \\
\text { ratio }\end{array}$ & \multicolumn{2}{|c|}{ 95.0\% C.I.for $\mathrm{EXP}(B)$} \\
\hline & & & $\operatorname{Exp}(B)$ & Lower & Upper \\
\hline GENDER (male) & .030 & .003 & $1.030 *$ & 1.024 & 1.037 \\
\hline \multicolumn{6}{|l|}{$\mathrm{AGE}^{\mathrm{a}}$} \\
\hline 70-74 years & -.117 & .004 & $.890 *$ & .883 & .897 \\
\hline 75-79 years & -.158 & .004 & $.854 *$ & .846 & .861 \\
\hline 80-84 years & -.442 & .005 & $.642 *$ & .636 & .649 \\
\hline 85 \& over & -.160 & .007 & $.852 *$ & .841 & .863 \\
\hline \multicolumn{6}{|l|}{ PRIVATE } \\
\hline Hlth Ins Ancillary & .650 & .005 & $1.915^{*}$ & 1.896 & 1.934 \\
\hline No Private Insurance & -.250 & .005 & $.779 *$ & .771 & .786 \\
\hline \multicolumn{6}{|l|}{$\mathrm{COB}^{\mathrm{b}}$} \\
\hline Australia & -.319 & .004 & $.727^{*}$ & .721 & .733 \\
\hline English speaking & -.353 & .005 & $.702 *$ & .695 & .710 \\
\hline \multicolumn{6}{|l|}{ STATE $^{\mathrm{C}}$} \\
\hline VIC & -.386 & .004 & $.680 *$ & .674 & .685 \\
\hline
\end{tabular}




\begin{tabular}{|c|c|c|c|c|c|}
\hline QLD & .189 & .004 & $1.208^{*}$ & 1.198 & 1.219 \\
\hline SA & .033 & .006 & $1.034 *$ & 1.022 & 1.046 \\
\hline WANT & -.219 & .006 & $.803^{*}$ & .794 & .812 \\
\hline TAS & -.620 & .011 & $.538^{*}$ & .527 & .549 \\
\hline \multicolumn{6}{|l|}{ REGION $^{\mathrm{d}}$} \\
\hline Regional & -.380 & .004 & $.684^{*}$ & .678 & .689 \\
\hline Remote & -.224 & .005 & $.799 *$ & .791 & .807 \\
\hline \multicolumn{6}{|l|}{ EDUCATION $^{\mathrm{e}}$} \\
\hline Higher/Pgrad dip/Bch & .504 & .007 & $1.656^{*}$ & 1.633 & 1.679 \\
\hline UGrad dip, Ass Dip & .718 & .007 & $2.051^{*}$ & 2.024 & 2.079 \\
\hline No post-school qual & -.108 & .004 & $.898^{*}$ & .891 & .905 \\
\hline \multicolumn{6}{|l|}{ HEALTH $^{\mathrm{f}}$} \\
\hline Very good & -.129 & .006 & $.879^{*}$ & .869 & .889 \\
\hline Good & -.339 & .006 & $.713^{*}$ & .705 & .721 \\
\hline Fair & -.299 & .006 & $.742^{*}$ & .733 & .750 \\
\hline Poor & -.371 & .007 & $.690^{*}$ & .681 & .700 \\
\hline HH INCOME & .073 & .001 & $1.076^{*}$ & 1.074 & 1.078 \\
\hline Concession Card & .010 & .007 & 1.010 & .997 & 1.023 \\
\hline Constant & -.007 & .011 & 993 & & \\
\hline
\end{tabular}

* significant odds ratios, $P<0.001$

a. Age 65-69 is the referent

b. COB non English speaking in the referent

c. NSW is the referent

d. Remote is the referent

e. Basic skill vocational is referent

f. Excellent is referent

Source: Derived from the National Health Survey 2004-2005 (소 2005)

Table 3 Geographical Location Segregated by State ${ }^{a}$, Australia, 2005

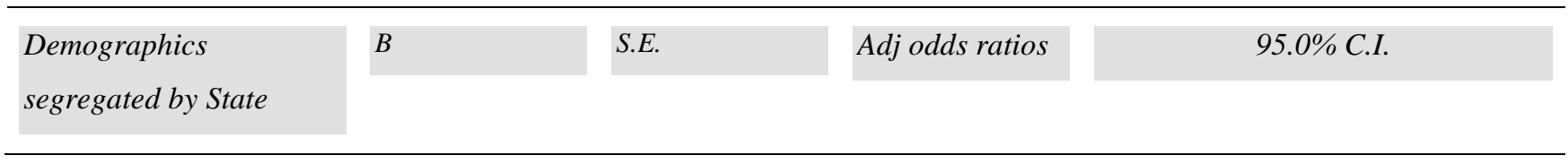




\begin{tabular}{|c|c|c|c|c|c|}
\hline \multicolumn{6}{|l|}{$\operatorname{NSW}\left(R^{2}=0.164\right)$} \\
\hline Regional & -.401 & .007 & $.670 * * *$ & .660 & .679 \\
\hline Remote & .255 & .008 & $1.290 * * *$ & 1.269 & 1.311 \\
\hline Family income & .064 & .001 & $1.066^{* * *}$ & 1.063 & 1.069 \\
\hline Concession card & -.367 & .011 & $.693^{* * *}$ & .678 & .708 \\
\hline \multicolumn{6}{|l|}{ VIC $\left(R^{2}=0.169\right)$} \\
\hline Regional & -.737 & .009 & $.479 * * *$ & .470 & .487 \\
\hline Remote & -.365 & .013 & $.694 * * *$ & .677 & .712 \\
\hline Family income & -.003 & .002 & $.997 *$ & .994 & 1.001 \\
\hline Concession card & .447 & .014 & $1.563^{* * *}$ & 1.522 & 1.606 \\
\hline \multicolumn{6}{|l|}{ Qld $\left(R^{2}=0.148\right)$} \\
\hline Regional & -.336 & .008 & $.715^{* * *}$ & .703 & .726 \\
\hline Remote & -.530 & .011 & $.589 * * *$ & .577 & .601 \\
\hline Family income & .108 & .002 & $1.113^{* * *}$ & 1.109 & 1.118 \\
\hline Concession card & .122 & .016 & $1.130 * * *$ & 1.094 & 1.167 \\
\hline \multicolumn{6}{|l|}{$\mathrm{SA}\left(R^{2}=0.226\right)$} \\
\hline Regional & -.036 & .017 & $.965 * *$ & .934 & .997 \\
\hline Remote & -.751 & .016 & $.472 * * *$ & .457 & .487 \\
\hline Family income & .119 & .003 & $1.126 * * *$ & 1.118 & 1.134 \\
\hline Concession card & -.119 & .030 & $.888 * * *$ & .838 & .942 \\
\hline \multicolumn{6}{|l|}{ WA/NT $\left(\mathrm{R}^{2}=.188\right)$} \\
\hline Regional & -.227 & .015 & $.797 * * *$ & .774 & .821 \\
\hline Remote & -.552 & .017 & $.576 * * *$ & .557 & .596 \\
\hline Family income & .143 & .003 & $1.154^{* * *}$ & 1.147 & 1.161 \\
\hline Concession card & .060 & .031 & $1.061^{* *}$ & .999 & 1.127 \\
\hline \multicolumn{6}{|l|}{$\operatorname{TAS}\left(\mathrm{R}^{2}=.262\right)$} \\
\hline Regional & .076 & .024 & $1.079 * * *$ & 1.030 & 1.130 \\
\hline Family income & .106 & .006 & $1.112 * * *$ & 1.099 & 1.125 \\
\hline Concession card & -.939 & .054 & $.391 * * *$ & .352 & .435 \\
\hline
\end{tabular}


***P $\leq 0.01, * * P \leq 0.05, * P \leq 0.10$

a. Control variables include gender, age, private health insurance, $\mathrm{COB}$, education, health status.

Source: Derived from the National Health Survey 2004-2005 (스S 2005)

Table 4 Dental Services Expenditure, Current Prices, by State, 2004-05

\begin{tabular}{|c|c|c|c|c|c|}
\hline State & $\begin{array}{l}\text { Expenditure (\$ } \\
\text { million) }\end{array}$ & $\begin{array}{l}\text { Mean resident } \\
\text { population }^{a}(\$\end{array}$ & $\begin{array}{l}\text { Expenditure } \\
\text { per capita (\$) }\end{array}$ & $\begin{array}{l}\text { Odds Ratio (visiting dentist) } \\
\text { from Table } 3\end{array}$ & $\begin{array}{l}\text { Rank }^{b} \text { of } \\
\text { Odds Ratio }\end{array}$ \\
\hline & & million) & & & \\
\hline NSW & 143 & 6.749 & 21.19 & 1.00 & 3 \\
\hline Vic & 107 & 4.9948 & 21.42 & .680 & 5 \\
\hline Qld & 128 & 3.9259 & 32.60 & 1.208 & 1 \\
\hline WA/NT & 50 & 1.9944 & 25.07 & .803 & 4 \\
\hline SA & 49 & 1.5373 & 31.87 & 1.034 & 2 \\
\hline Tas & 11 & 0.4839 & 22.73 & .538 & 6 \\
\hline
\end{tabular}

a. The mean resident population is the population used internationally to derive per capita GDP. By examining health expenditure on a per person basis, the influence of changes in the overall size of the population is removed from the analysis (AIHW 2006).

b. From a ranking of 1 greatest, to 6 least.

Source: Table derived from Table 2 and the AIHW data (AIHW 2006). 